\title{
SURGICAL OUTCOMES OF SUBTROCHANTERIC FRACTURES OF FEMUR TREATED WITH PROXIMAL FEMORAL NAIL (PFN)
}

\author{
Jenson Isaac1, Vijay Krishna², Ranjith Kumar³, Shanmugavel ${ }^{4}$ \\ ${ }^{1}$ Assistant Professor, Department of Orthopaedics, Tagore Medical College. \\ ${ }^{2}$ Senior Resident, Department of Orthopaedics, Tagore Medical College. \\ 3 Senior Resident, Department of Orthopaedics, Tagore Medical College. \\ ${ }^{4}$ Senior Resident, Department of Orthopaedics, Tagore Medical College.
}

\section{ABSTRACT}

\section{BACKGROUND AND OBJECTIVES}

Subtrochanteric fractures of the femur remain one of the most challenging fractures facing orthopaedic surgeons. Most of the fractures in the elderly results from trivial fall from standing or walking, while in the younger age group it is mainly due to road traffic accidents. Closed management of these subtrochanteric fractures thus poses difficulties in obtaining and maintaining a reduction, making operative management the preferred treatment. Hence, this study is intended to determine the effectiveness of intramedullary fixation of subtrochanteric fractures with the proximal femoral nail and the complications involved in the management of subtrochanteric fractures.

\section{METHODOLOGY}

This is a prospective study of 90 cases of Subtrochanteric fracture admitted to Tagore Medical College and Hospitals between October 2013 and Jan 2016 treated with the proximal femoral nail. Cases were taken according to inclusion and exclusion criteria, i.e. fresh Subtrochanteric fracture in adults. Pathologic fractures, multiple fractures, fractures in children, old neglected fractures were excluded from the study.

\section{RESULTS}

In our study of 90 cases, there were 75 male and 15 female patients with age ranging from 17 years to 75 years with most patients in between $21-40$ years; $67 \%$ of the cases admitted were road traffic accidents, $23 \%$ due to fall from height and $10 \%$ due to trivial fall with right side being more common side affected. Russell and Taylor type IA fracture accounted for $40 \%$ of cases. Mean duration of hospital stay was 12 days and mean time of full weight bearing was 14 weeks in our patients. Out of 90 cases, 9 cases were lost in follow-up and 3 cases died. Good-to-excellent results were seen in $80 \%$ of cases in our study.

\section{CONCLUSION}

From our study, we conclude that PFN is a reliable implant for subtrochanteric fractures leading to high rate of bone union and minimal soft tissue damage. Intramedullary fixation has biological and biomechanical advantages, but the operation is technically demanding. Gradual learning and great patience are needed in order to make this method truly minimally invasive.

\section{KEYWORDS}

PFN, Subtrochanteric Fractures, Russell and Taylor Classification.

HOW TO CITE THIS ARTICLE: Isaac J, Krishna V, Kumar R, et al. Surgical outcomes of subtrochanteric fractures of femur treated with proximal femoral nail (PFN). J. Evolution Med. Dent. Sci. 2016;5(52):3373-3377, DOI: 10.14260/jemds/2016/779

\section{INTRODUCTION}

Subtrochanteric fractures are femoral fractures where the fractures occur below the lesser trochanter to $5 \mathrm{~cm}$ distally in the shaft of femur.[1] These fractures occur typically at the junction between trabecular bone and cortical bone where the mechanical stress across the junction is highest in the femur, which is responsible for their frequent comminution. These fractures account for $10 \%$ to $34 \%$ of all hip fractures.[2]

The subtrochanteric region is usually exposed to high stresses during activities of daily living. Axial loading forces through the hip joint, create a large moment arm with significant lateral tensile stresses and medial compressive

Financial or Other, Competing Interest: None.

Submission 13-05-2016, Peer Review 06-06-2016,

Acceptance 13-06-2016, Published 28-06-2016.

Corresponding Author:

Dr. Jenson Isaac,

Flat No. 4041, Estancia Town Ship,

GST Road, Guduvanchery,

Chennai-603202.

E-mail: docjenson@gmail.com

DOI: $10.14260 /$ jemds $/ 2016 / 779$ loads. In addition to the bending forces, muscle forces at the hip also create torsional effects that lead to significant rotational shear forces. During normal activities of daily living, up to 6 times the body weight is transmitted to the subtrochanteric region of the femur.

As a result of these high forces, the bone in this region is a thick cortical bone with less vascularity and results in increased potential for healing disturbances. Hence, subtrochanteric fracture is difficult to manage and associated with many complications.[3]

Closed management of these subtrochanteric fractures thus poses difficulties in obtaining and maintaining a reduction, making operative management the preferred treatment. The goal of operative treatment is restoration of normal length and angulation to restore adequate tension to the abductors and to start early mobilisation and weight bearing. Hence, the objective of this study is to determine the rate of union, complications, operative risks and functional outcomes in subtrochanteric fractures treated with the proximal femoral nail.[3] 


\section{METHODOLOGY}

The present study consists of 90 adult patients with subtrochanteric fractures of femur who were treated with PFN in Tagore Medical College and Hospitals between October 2013 and Jan 2016, after getting clearance from Institutional Ethical Committee and Academic Review Board. The fractures were classified according to Russell and Taylor classification; 78 cases were followed at regular intervals and 12 cases were lost to follow-up. Only fresh Subtrochanteric fractures in adults were included in the study. Pathological fractures, Fractures in children, Old neglected fractures and Periprosthetic fractures were excluded from the study.

As soon as the patient with suspected subtrochanteric fracture was seen, necessary clinical and radiological evaluation was done and admitted to the ward after necessary resuscitation and splintage with skeletal traction. Routine blood investigations were done on all patients. With adequate preoperative planning, which includes measuring the diameter of the femur at the level of Isthmus for nail diameter and neck shaft angle by goniometer. In our study, we used the standard length PFN of $250 \mathrm{~mm}$ with distal diameter of 9,10 , $11 \mathrm{~mm}$.

\section{Operative Technique}

The patient is placed in supine position on fracture table with adduction of the affected limb by 10-15 degrees and closed reduction of the fracture was done by the traction and internal rotation and checked under image intensifier. Open reduction is performed if closed reduction failed. Prophylactic antibiotic is given in all patients 30 minutes before surgery.

A $5 \mathrm{cms}$ longitudinal incision was taken proximal from the tip of the greater trochanter. A parallel incision was made in fascia lata and gluteus medius was split in line with the fibres. Tip of greater trochanter is exposed. In AP view on C-arm, the entry point is on tip of greater trochanter. Then medullary canal entered with a curved bone awl; the guidewire is inserted into the medullary canal. Using a cannulated conical reamer, proximal femur is reamed for a distance of about 7 cms. After confirming satisfactory fracture reduction, an appropriate size nail as determined preoperatively is assembled to insertion handle and inserted manually.

A $2.8 \mathrm{~mm}$ guidewire is inserted through the drill sleeve after a stab incision. A second $2.8 \mathrm{~mm}$ guidewire is inserted through the drill sleeve above the first one for hip pin. Drilling is done over $2.8 \mathrm{~mm}$ guidewire until the drill is $8 \mathrm{~mm}$ short of tip of the guidewire. Neck screw is inserted using cannulated screw driver. Similarly, appropriate length hip pin is inserted. Length and position of the screw are confirmed with C-arm image. Distal locking is usually performed with two cortical screws. Locking screw is inserted and position confirmed with image intensifier. Wound closed in layers and sterile dressing applied over wound and compression bandage given.

Postoperatively, patient's pulse, blood pressure, respiration and temperature were monitored. Antibiotics were continued in postoperative period. Suture removed on the 12th post-operative day. Patients were taught Quadriceps static exercise and knee mobilisation in immediate postoperative period. Patients were taught gait training before discharge from hospital.

All patients were followed up at 4 weeks, 12 weeks and every 6 weeks thereafter till fracture union is noted; then at 6 months, 9 months and 1 year. At each visit, patient was assessed clinically regarding hip and knee function, walking ability, fracture union, deformity and shortening. Hip function was assessed by Harris Hip score. X-ray of the pelvis with both hips was taken to assess fracture union and implant bone interaction (Figure 1).

\section{OBSERVATION AND RESULTS.}

In our study, maximum age was 75 years and minimum age was 17 years. Most of the patients were between 21-40 years. Mean age was 37.53 years. The number of male patients in our series were 75 and female were 15. Right side was affected in 66 cases and left in 24 cases. The most common mode of injury in our series were road traffic accidents accounting for 60 cases followed by fall from height in 21 cases and trivial fall in 9 cases. The 90 subtrochanteric fractures in our study were classified according to Russell and Taylor classification. In our study we had 36 cases of IA, 33 cases of IB and 21 cases of IIA Russell and Taylor classification. All the patients were operated at an average interval of 10.6 days from the day of trauma. All the patients' intraoperative details were noted in terms of the duration of surgery, ease of reduction, complications, radiation exposure and amount of blood loss. In our series, we had 12 cases of superficial wound infection, which required intravenous antibiotics for 3 weeks' period. No other complications like Deep Venous Thrombosis, Systemic Infection, Acute Respiratory Distress Syndrome, Fat Embolism, etc.

\begin{tabular}{|c|c|}
\hline Mean duration of surgery & $105 \mathrm{~min}$ \\
\hline \multicolumn{2}{|l|}{ Reduction } \\
\hline Easy & 60 cases \\
\hline Difficult & 30 cases \\
\hline Mean blood loss (mL) & $180 \mathrm{~mL}$ \\
\hline Mean duration of radiation (sec) & $140 \mathrm{sec}$ \\
\hline Table 1: Intraoperative 1 & \\
\hline
\end{tabular}

\begin{tabular}{|c|c|c|}
\hline Complications & $\begin{array}{c}\text { No. of } \\
\text { Cases (90) }\end{array}$ & Percentage \\
\hline $\begin{array}{c}\text { Failure to Achieve } \\
\text { Closed Reduction }\end{array}$ & 24 & $26.66 \%$ \\
\hline Fracture of Lateral Cortex & 6 & $6.66 \%$ \\
\hline Varus Angulation & 6 & $6.66 \%$ \\
\hline $\begin{array}{c}\text { Failure to Put } \\
\text { Derotation Screw }\end{array}$ & 18 & $20 \%$ \\
\hline Failure to Lock Distally & 3 & $3.33 \%$ \\
\hline Jamming of Nail & 0 & $0 \%$ \\
\hline Drill Bit Breakage & 0 & $0 \%$ \\
\hline Guidewire Breakage & 3 & $3.33 \%$ \\
\hline \multicolumn{2}{|c|}{ Table 2: Intraoperative Complications of PFN } \\
\hline
\end{tabular}

\begin{tabular}{|c|c|c|}
\hline $\begin{array}{c}\text { Delayed } \\
\text { Complications }\end{array}$ & $\begin{array}{c}\text { No. of } \\
\text { Cases (78) }\end{array}$ & Percentage \\
\hline Hip Joint Stiffness & 12 & 11.5 \\
\hline Knee Joint Stiffness & 3 & 3.84 \\
\hline Delayed Union & 6 & 7.69 \\
\hline Shortening & 3 & 3.84 \\
\hline Implant Failure & 6 & 7.69 \\
\hline Varus Angulation & 6 & 7.69 \\
\hline Z Effect/Reverse Z Effect & 6 & 7.69 \\
\hline \multicolumn{2}{|c|}{ Table 3: Delayed Complications } \\
\hline
\end{tabular}


The average duration of hospital stay following surgery was 12 days ranging from 10 to 14 days. All patients were followed up at 4 weeks, 12 weeks and every 6 weeks thereafter till fracture union is noted. Then at 6 months, 9 months and 1 year, 9 patients failed to attend the first follow-up and were lost for further follow-up and 3 patients expired due to cardiac failure. At each follow-up radiographs of upper femur and hip were taken to assess the fracture union, implant failure and screw cut out.

Radiological union was said to be achieved on the evidence of obliteration of fracture lines and trabecular continuity between the two fragments on antero-posterior and lateral Xrays in three cortices (Figure 2).

\begin{tabular}{|c|c|c|}
\hline Union in Weeks & Frequency & Percentage \\
\hline $0-12$ wks. & 6 & 7.7 \\
\hline $13-16$ wks. & 12 & 15.4 \\
\hline $17-20$ wks. & 27 & 34.6 \\
\hline $21-24$ wks. & 21 & 26.9 \\
\hline $25-28$ wks. & 6 & 7.7 \\
\hline$>28$ wks. & 6 & 7.7 \\
\hline Total Table 4: Union in Weeks \\
\hline \multicolumn{2}{|c|}{} \\
\hline
\end{tabular}

\section{Anatomical Results}

Anatomical results were assessed on 78 patients available for follow-up by presence or absence of shortening, varus deformities and range of movements in hip and knee joints; $77 \%$ of the cases had good results and $23 \%$ had fair results.

\begin{tabular}{|c|c|c|}
\hline Results-Anatomical & Frequency & Percentage \\
\hline Restriction of hip ROM & 12 & 11.5 \\
\hline Shortening $>1 \mathrm{~cm}$ & 3 & 3.9 \\
\hline Varus deformity & 6 & 7.7 \\
\hline Good & 57 & 76.9 \\
\hline Total & 78 & 100 \\
\hline \multicolumn{3}{|c|}{ Table 5: Anatomical Results } \\
\hline
\end{tabular}

\section{Functional Results}

Functional results were assessed in 78 cases available for follow-up by Harris Hip scoring system.

\begin{tabular}{|c|c|c|}
\hline Results & Frequency & Percentage \\
\hline Excellent & 21 & $\mathbf{2 6 . 9}$ \\
\hline Good & 42 & $\mathbf{5 3 . 9}$ \\
\hline Fair & 12 & $\mathbf{1 1 . 5}$ \\
\hline Poor & 6 & $\mathbf{7 . 7}$ \\
\hline Total & $\mathbf{7 8}$ & $\mathbf{1 0 0}$ \\
\hline \multicolumn{3}{|c|}{ Table 6: Functional Results } \\
\hline
\end{tabular}

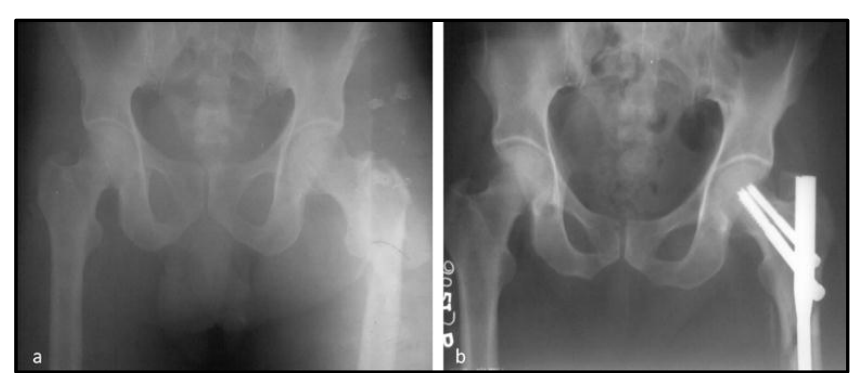

Fig. 1: Pre and Postoperative X-ray of a Patient with Subtrochanteric Fracture showing Displaced Fracture of Left Femur and Treated with PFN

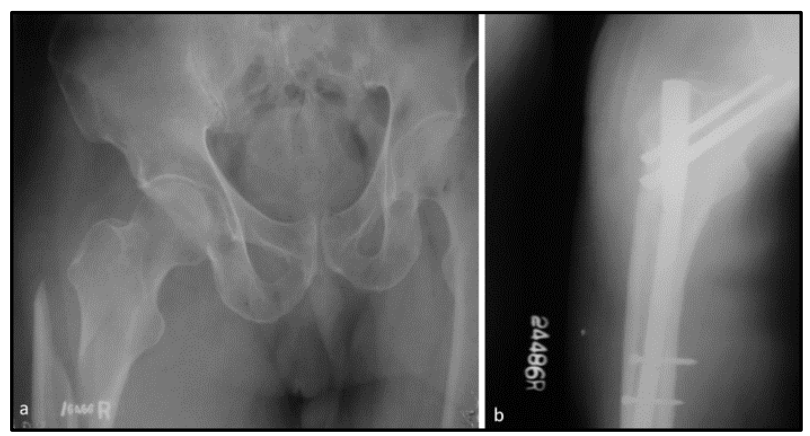

Fig. 2: Pre-operative X-ray showing Long Spiral Subtrochanteric Fracture (a) and Post-Operative X-ray showing Fracture Union in $13^{\text {th }}$ Post-operative Week

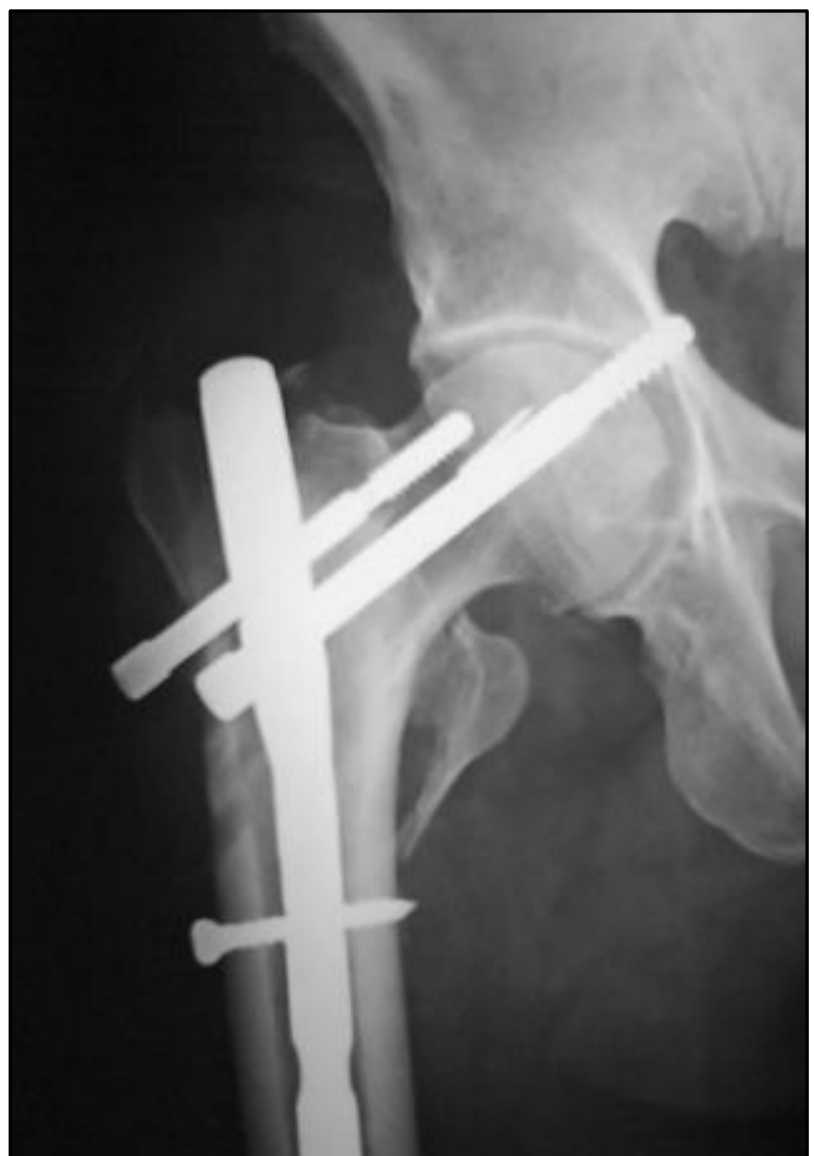

Fig. 3: Z-Effect (Proximal Migration of Screw in Hip Joint) in Proximal Femoral Nail Fixation occurred in One of Our Case for which Implant Removal Done

\section{DISCUSSION}

Unlike osteoporotic trochanteric fractures, subtrochanteric fractures are usually the result of high-energy trauma and often subjected to significant displacement and great difficulty in close reduction through traction. The high incidence of delayed union, malunion and non-union of fractures has left conservative treatment as advocated by DeLee et al, abolished in modern trauma care.[4]

Allowing a minimally open approach, intramedullary nailing is closely linked to "biological internal fixation," in addition to its mechanical benefits over plate fixation. Intramedullary fixation allows the surgeon to minimise soft tissue dissection thereby reducing surgical trauma, blood loss, infection and wound complications. ${ }^{[5,6]}$ 
The AO ASIF in 1996, therefore, developed the Proximal Femoral Nail to reduce the risk of implant related complications. Therefore, in addition to the $8 \mathrm{~mm}$ load bearing femoral neck screw, the PFN has a $6.5 \mathrm{~mm}$ anti-rotation screw to increase the rotational stability of the neck fragment. An anatomic 60 neck valgus bend in the coronal plane, a narrower distal diameter and distal flexibility of the nail eliminates the need for routine reaming of the femoral shaft and also minimises stress concentration and tension in the femoral shaft. This should reduce the risk of intraoperative and postoperative femoral shaft fractures.

PFN also has all the advantages of an intramedullary device such as decreasing the moment arm, can be inserted by closed technique which retains the fracture haematoma, decreases blood loss, minimizes soft tissue dissection and wound infections. In an experimental study, Gotze et al (1998) compared the loadability of osteosynthesis of unstable per and subtrochanteric fractures and found that the PFN could bear the highest loads of all devices.[7]

The aim of our study was to assess the epidemiology and functional outcomes of subtrochanteric fractures with this newer method of intramedullary fixation with the proximal femoral nail. We assessed the results with respect to intraoperative details, post-operative results and functional outcome.

In 2002, Inger B Schipper in his study on biomechanical evaluation of PFN also concluded that if the hole through the nail of the hip pin was modified to a slot, there is a significant reduction of axial loads on hip pin, thereby reducing the cut out risk.[8] In our study, we had 6 cases of non-union due to breakage of the implant (7.6\%).

Werner et al was the first who introduced the term Zeffect, detected in $5(7.1 \%)$ of 70 cases (Figure 3). The incidence of the cut-out of the neck screw in this study was $8.6 \%$. The Z-effect phenomenon is referred as a characteristic sliding of the proximal screws to opposite directions during the postoperative weight-bearing period.[9] In our study, we had Z-effect in 3 cases (3.8\%). The reverse Z-effect described by Boldin et al occurred with movement of the hip pin towards the lateral side, which required early removal. The mechanism is similar, but here the hip pin is sliding back, whereas the neck screw remains impacted to the hole of the nail. The authors in an effort to prevent the Z-effect phenomenon suggest the use of a "ring" on the lateral side of the hip pin.[7] In our study, we had 3 cases with reverse Z-effect (3.8\%).

The most recent study evaluating the use of PFN is from Fogagnolo et al, who reported 46 patients with an average rate

of intraoperative technical or mechanical complications of $23.4 \%$. They also reported 2 implant failures and 1 fracture below the tip of the nail.[9] In our study, we had 6 cases with implant failure $(7.6 \%)$ and intraoperative technical problems like failure to put derotation screws in 18 cases $(20 \%)$, guidewire breakage in 3 cases $(3.3 \%)$ and failure in putting locking bolts in 3 cases (3.3\%).

Daniel FA Menzes et al and Axel Gamulin (2005) in a clinical study of 155 consecutive patients treated with proximal femoral nail, reported failure of fixation in $2 \%$, femoral shaft in $0.7 \%$, fixation failures included one cut out, one delayed fracture healing and one lateral displacement of the antirotation screw.[10] In our study, failure of fixation occurred in $16 \%$ (12 cases), which includes 6 cases of lateral cortex fracture due to wrong entry point and 6 cases of nonunion with implant breakage. We had no cases of femoral shaft fracture in our study.

Simmermacher et al (1999) in a clinical multicenter study, reported technical failures of the PFN after poor reduction, malrotation or wrong choice of screws in $5 \%$ of the cases. A cut-out of the neck screw occurred in $0.6 \% .{ }^{[11]}$ In our study, we had $16 \%$ failure rate with 6 cases of non-union due to implant breakage and 6 cases of delayed union. We had a re-operation rate of $20 \%$ in our study due to implant breakage and mechanical problems like Z-effect and reverse Z-effect.

\begin{tabular}{|c|c|c|c|c|c|}
\hline & $\begin{array}{c}\text { C Boldin } \\
\text { et al[7] }\end{array}$ & $\begin{array}{c}\text { Dominigo } \\
\text { et al[9] }\end{array}$ & $\begin{array}{c}\text { Fogagnolo } \\
\text { et al[9] }\end{array}$ & $\begin{array}{c}\text { Simmer- } \\
\text { macher } \\
\text { et al[11] }\end{array}$ & $\begin{array}{c}\text { Our } \\
\text { Study }\end{array}$ \\
\hline $\begin{array}{c}\text { No. of } \\
\text { Patients }\end{array}$ & 55 & 295 & 46 & 191 & 90 \\
\hline Cut Out & 2 & 4 & 5 & 1 & 0 \\
\hline Z Effect & 3 & - & - & - & 3 \\
\hline $\begin{array}{c}\text { Reverse Z } \\
\text { effect }\end{array}$ & 2 & - & - & - & 3 \\
\hline $\begin{array}{c}\text { Implant } \\
\text { Failure }\end{array}$ & - & - & 2 & 1 & 6 \\
\hline $\begin{array}{c}\text { Femoral } \\
\text { Fracture } \\
\text { Below the } \\
\text { Tip }\end{array}$ & - & 1 & 1 & - & - \\
\hline $\begin{array}{c}\text { Re } \\
\text { Operation } \\
\text { Rate }\end{array}$ & $18 \%$ & $3 \%$ & $19 \%$ & $7 \%$ & $20 \%$ \\
\hline $\begin{array}{c}\text { Open } \\
\text { Reduction }\end{array}$ & $10 \%$ & - & - & - & $27 \%$ \\
\hline \multicolumn{7}{|c|}{ Table 7: Mechanical Complications of PFN System } \\
\hline
\end{tabular}

\begin{tabular}{|c|c|c|c|c|c|}
\hline & C Boldin et al[7] & Ekstrom et al[12] & Menzes et al[10] & Lei-Sheng et al[13] & Our Study \\
\hline No. of patients & 55 & 105 & 155 & 49 & 90 \\
\hline Duration of surgery & $68 \mathrm{~min}$ & $77 \mathrm{~min}$ & $76 \mathrm{~min}$ & $46 \mathrm{~min}$ & $105 \mathrm{~min}$ \\
\hline Bony Union (Months) & $100 \%$ (4 months) & $100 \%$ (9 months) & $99 \%$ (6 months) & $98 \%$ (6 months) & $85 \%$ (6 months) \\
\hline Failure of Fixation & $0 \%$ & \begin{tabular}{|l|}
$11 \%$ \\
\end{tabular} & $2 \%$ & $0 \%$ & $7.7 \%$ \\
\hline Delayed Union & - & - & $0.7 \% \%$ & $2 \%$ & $7.7 \%$ \\
\hline Open Reduction & $10 \%$ & - & $1.3 \%$ & $34.6 \%$ & $20 \%$ \\
\hline Re-operation Rate & $10 \%$ & $9 \%$ & $12 \%$ & & $27 \%$ \\
\hline Duration of Hospital Stay & & 12 days & 17 days & & 12 days \\
\hline
\end{tabular}

In our 90 cases, 9 patients were lost for follow-up and 3 cases died due to associated medical problems. Excellent results were seen in $27 \%$, good in $53 \%$ cases, fair in $12 \%$ cases and poor in $8 \%$ cases treated by PFN.

\section{CONCLUSION}

Subtrochanteric femoral fractures are usually treated surgically. In the last decade, extramedullary methods of fixation with various angular plates or with a compression hip 
screw with a plate are more and more replaced by newer intramedullary techniques because of their advantages: The surgical procedure is faster, the blood loss is smaller, the bone healing mainly remains in the reduced position with a biomechanically strong fixation, what allows earlier weight bearing on the bone with less local and general complications. Because of increasing occurrence of subtrochanteric fractures in younger age active males, higher demand is placed on treating surgeon to restore near normal function of leg.

Osteosynthesis with the proximal femoral nail offers the advantages of high rotational stability of the head-neck fragment. Proximal femoral nail has the advantage of collapse at fracture site and is biomechanically sound as it is an intramedullary device. Postoperatively, early mobilization can begin as the fixation is rigid and the implant design.

From our study, we conclude that PFN is a reliable implant for subtrochanteric fractures leading to high rate of bone union and minimal soft tissue damage. Intramedullary fixation has biological and biomechanical advantages, but the operation is technically demanding. Gradual learning and great patience is needed in order to make this method truly minimally invasive.

\section{REFERENCES}

1. Heckman JD, Bucholz RW. Rockwood and Green's fractures in adults. $6^{\text {th }}$ ed. Lippincott Williams \& Wilkins. 2001

2. Canale ST. Campbellś operative orthopaedics. Mosby 1998.

3. McLaurin TM, Lawler EA. Treatment modalities for subtrochanteric fractures in the elderly. Techniques in Orthopaedics 2008;23(3):232-48.

4. DeLee JC, Clanton TO, Rockwood CA. Closed treatment of subtrochanteric fractures of the femur in a modified castbrace. J Bone Joint Surg Am 1981;63(5):773-9.
5. Leung KS, So WS, Shen WY, et al. Gamma nails and dynamic hip screws for peritrochanteric fractures a randomised prospective study in elderly patients. J Bone Joint Surg Br 1992;74(3):345-51.

6. Hinton R, Smith GS. The association of age, race, and sex with the location of proximal femoral fractures in the elderly. J Bone Joint Surg Am 1993;75(5):752-9.

7. Boldin C, Seibert FJ, Fankhauser F, et al. The proximal femoral nail-a minimal invasive treatment of unstable proximal femoral fractures: a prospective study of 55 patients with a follow-up of 15 months. Acta Orthop Scand 2003;74(1):53-8.

8. Schipper IB, Stephen B, Dieter W, et al. Biomechanical evaluation of the proximal femoral nail. Clinical Orthopaedics and Related Research 2002;405:277-86.

9. Tyllianakis M, Panagopoulos A, Papasimos S, et al. Treatment of extracapsular hip fractures with the proximal femoral nail (PFN): long term results in 45 patients. Acta Orthop Belg 2004;70(5):444-54.

10. Menezes DF, Gamulin A, Noesberger B. Is the proximal femoral nail a suitable implant for treatment of all trochanteric fractures? Clin Orthop Relat Res 2005;439:221-7.

11. Simmermacher RK, Bosch AM, Werken CVD. The AO/ASIF-proximal femoral nail (PFN): a new device for the treatment of unstable proximal femoral fractures. Injury 1999;30(5):327-32.

12. Ekstrom W, Karlsson-Thur C, Larsson S, et al. Functional outcome in treatment of unstable trochanteric and subtrochanteric fractures with the proximal femoral nail and the medoff sliding plate. J Orthop Trauma 2007;21(1):18-25.

13. Jiang LS, Shen L, Dai LY. Intramedullary fixation of subtrochanteric fractures with long proximal femoral nail or long gamma nail: technical notes and preliminary results. Ann Acad Med Singapore 2007;36(10):821-6. 